\title{
estimation of the LaSer Cut Perpendicularity USING LINEAR REGRESSION ANALYSIS
}

\author{
Mirza Pasic, Derzija Begic-Hajdarevic \& Izet Bijelonja
}
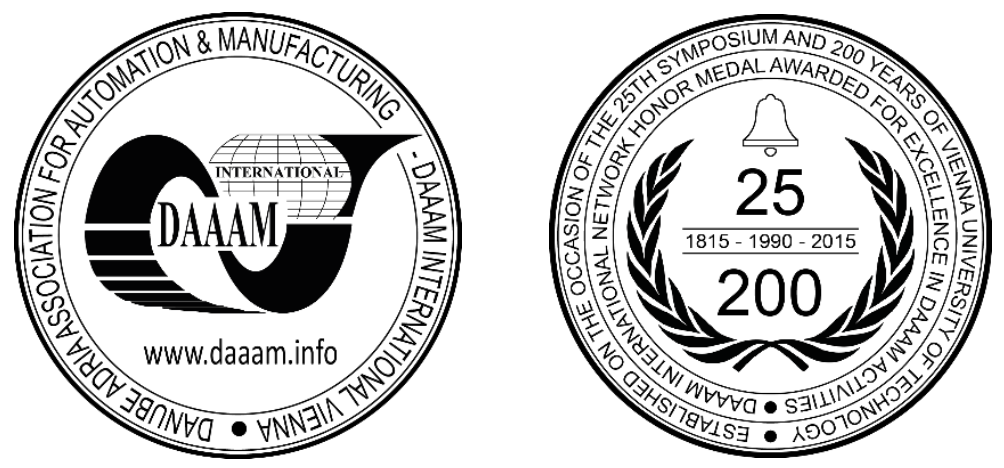

This Publication has to be referred as: Pasic, M[irza]; Begic-Hajdarevic, D[erzija] \& Bijelonja, I[zet] (2017). Estimation of the Laser Cut Perpendicularity Using Linear Regression Analysis, Proceedings of the 28th DAAAM International Symposium, pp.1083-1089, B. Katalinic (Ed.), Published by DAAAM International, ISBN 978-3-90273411-2, ISSN 1726-9679, Vienna, Austria

DOI: $10.2507 / 28$ th.daaam.proceedings. 150

\begin{abstract}
The aim of this paper is to develop a mathematical model using a linear regression analysis for the laser cut perpendicularity depending on the cutting parameters and to compare the values of the cut perpendicularity according to ISO 9013:2002 (E) standard. Cutting parameters that are used as independent variables in this research are: laser power $P$, cutting speed $v$ and assist gas pressure $p$. During the experiment 75 samples of 1.4307 DIN stainless steel and $1 \mathrm{~mm}$ of thickness were cut on HSG fiber laser using nitrogen $N_{2}$ as an assist gas. Each sample was cut using different combination of values of independent variables. Cut perpendicularity was measured on these samples with total of 225 measurements. Obtained results show that the cutting speed is only significant variable in the model and that the linear regression analysis is suitable for the analysis of the cut perpendicularity. Every experimental value of the cut perpendicularity is located in the first quality category according to ISO 9013:2002 (E) standard.
\end{abstract}

Keywords: laser cutting; fiber laser; regression analysis; cut perpendicularity; stainless steel

\section{Introduction}

Multiple regression analysis is shown to be useful technique for mathematical modeling of many industrial engineering processes including material cutting process. These processes happen as result of interaction of variables. Some of these variables are independent, while some are dependent. To explain these processes, it is important to determine relations between these variables and to create the model that will explain certain process and prediction of dependent variables [1].

During the laser cutting process there are many variables. Some of them are independent variables, known as cutting parameters, defined before laser cutting process, while some are dependent variables which determine cut quality and their values depend on variability of independent variables. Regression analysis is used to obtain mathematical model that explains variability of dependent variables based on variability of independent variables. 
Nowadays in many fields like informatics, measurement technique, telecommunications and medicine there is increasing need for the high precision of small parts and for reduction of material and energy used in production processes. The use of laser is more and more present and necessary in industrial practice. Laser cutting is the modern cutting method and its use is in expansion because of many advantages in comparison to conventional cutting processes. Laser cutting is thermal cutting process and has advantages even to other thermal cutting processes [2, 3]. Advantages of the laser cutting are high quality of the cut surface, narrow kerf width, low heat affected zone and sharp and perpendicular edges. However, during the laser cutting process the cut quality can vary depending on many factors such as cutting parameters, type of assist gas and type of material [4].

Many papers examine influence of these factors on certain aspects of the cut quality. In [5] influence of cutting speed, focus position, assist gas pressure and stand-off on surface roughness $R_{a}$ and heat affected zone using two different types of steel is investigated. It is concluded that $R_{a}$ is smaller when the cutting speed is higher and with focus position above the surface, while the assist gas pressure does not affect $R_{a}$.

In [6] dependency of kerf width is analyzed based on variability of laser power and type of assist gas. The cutting is performed on 3 stainless steel plates of different thickness. It is concluded that with increase of energy per unit of length there is increase of the kerf width. With the same laser power kerf width is higher if nitrogen is used as an assist gas instead of oxygen.

In [7] influence of laser power and cutting speed on surface roughness $R_{a}$ is examined during $\mathrm{CO}_{2}$ laser cutting using oxygen as assist gas. Influence of increase of cutting speed on surface roughness and heat affected zone is analyzed in [8]. Research [9] uses regression analysis for development of model that describes influence of laser power on kerf width, surface roughness, heat affected zone and striation frequency.

Regression analysis is shown to be very reliable method for analysis of parameters and quality of laser cutting process. Analysis of research papers shows that general model of dependency of the laser cutting quality on cutting parameters has not be developed yet, but each experiment is special case depending of laser type, type of assist gas, thickness of material etc.

In this paper regression analysis is used to analyze cut perpendicularity with respect to cutting parameters: laser power, cutting speed and assist gas pressure during fiber laser cutting with $N_{2}$ as assist gas. Multiple regression analysis is performed to develop mathematical model to predict cut perpendicularity and to determine which cutting parameters are significant for cut perpendicularity.

\section{Experimental setup}

In this experiment 75 samples of 1.4307 DIN (X2CrNi18-9) stainless steel of $1 \mathrm{~mm}$ of thickness were cut on HSG fiber laser using nitrogen $N_{2}$ as an assist gas. HSG fiber laser with nominal power of $1000 \mathrm{~W}$ was used in this experiment. Cutting parameters that were varied in this experiment were laser power $P$, cutting speed $v$ and assist gas pressure $p$. These cutting parameters were used as independent variables in the linear regression analysis. During cutting process five different values of laser power and cutting speed and three different values of assist gas pressure were used. Those values are shown in table 1 , table 2 and table 3.

\begin{tabular}{|c|c|}
\hline Laser Power $\boldsymbol{P}$ & Values \\
\hline$P_{1}$ & $800 \mathrm{~W}$ \\
\hline$P_{2}$ & $850 \mathrm{~W}$ \\
\hline$P_{3}$ & $900 \mathrm{~W}$ \\
\hline$P_{4}$ & $950 \mathrm{~W}$ \\
\hline$P_{5}$ & $1000 \mathrm{~W}$ \\
\hline
\end{tabular}

Table 1. Laser power values

\begin{tabular}{|c|c|}
\hline Cutting speed $\boldsymbol{v}$ & Values \\
\hline$v_{1}$ & $320 \mathrm{~mm} / \mathrm{s}$ \\
\hline$v_{2}$ & $300 \mathrm{~mm} / \mathrm{s}$ \\
\hline$v_{3}$ & $280 \mathrm{~mm} / \mathrm{s}$ \\
\hline$v_{4}$ & $260 \mathrm{~mm} / \mathrm{s}$ \\
\hline$v_{5}$ & $240 \mathrm{~mm} / \mathrm{s}$ \\
\hline
\end{tabular}

Table 2. Cutting speed values 


\begin{tabular}{|c|c|}
\hline Assist gas pressure $\boldsymbol{p}$ & Values \\
\hline$p_{1}$ & $1 \mathrm{bar}$ \\
\hline$p_{2}$ & $1,3 \mathrm{bar}$ \\
\hline$p_{3}$ & $2 \mathrm{bar}$ \\
\hline
\end{tabular}

Table 3. Assist gas pressure values

Cutting parameters that were constant during the cutting process are presented in table 4 .

\begin{tabular}{|c|c|}
\hline Constant cutting parameters & Values \\
\hline Focus position & $-1 \mathrm{~mm}$ \\
\hline Distance of the nozzle & $1 \mathrm{~mm}$ \\
\hline Diameter of the nozzle & $1,5 \mathrm{~mm}$ \\
\hline
\end{tabular}

Table 4. Values of cutting parameters that were constant during the cutting process

Each sample was made with different combination of values of cutting parameters. There are 75 different combinations of values of cutting parameters and thus 75 samples were cut. Kerf width was measured by microscope Mitutoyo TM 505 and camera Motic 10 MP. Camera was placed on the microscope and they both were connected to computer via software Motic Images Plus 3.0.

On each sample nine places were marked on both input and output side of the laser beam side of the sample. By microscope and camera, on each marked spot, kerf was captured and the picture was downloaded to the computer. After that kerf width was measured on each captured picture using software Motic Images Plus 3.0. Nine measurements of the kerf width were made on each side of the sample, leading to 675 measurements for input and 675 measurements for output side of laser beam.

Next step was to calculate average values of the kerf width for input and output side of laser beam for each sample. Difference between average values of the kerf width on the input and the output side of the laser beam was calculated for each sample. This difference is called cut perpendicularity. There were 75 values of cut perpendicularity. After the measurements, linear regression analysis was done using cut perpendicularity as dependent variable and laser power $P$, cutting speed $v$ and assist gas pressure $p$ as independent variables. These 75 values of cut perpendicularity were categorized according to the ISO 9013:2002 (E) standard.

\section{Analysis of results}

Based on the experiment, backward multiple regression model was developed using sample size $n=75$ and number of independent variables $k=3$. Regression analysis results are given in table 5 .

\begin{tabular}{lr}
\hline \multicolumn{2}{c}{ Regression Statistics } \\
\hline Multiple R & 0,732 \\
R Square & 0,536 \\
Adjusted R Square & 0,517 \\
Standard Error & 6,961 \\
Observations & 75 \\
\hline
\end{tabular}

ANOVA

\begin{tabular}{|c|c|c|c|c|c|}
\hline & $\mathrm{df}$ & $\mathrm{SS}$ & MS & $\mathrm{F}$ & Significance F \\
\hline Regression & 3 & 3980,351 & 1326,784 & 27,379 & 0,000 \\
\hline Residual & 71 & 3440,641 & 48,460 & & \\
\hline Total & 74 & 7420,992 & & & \\
\hline
\end{tabular}

\begin{tabular}{lrrrrrr}
\hline & Coefficients & \multicolumn{1}{c}{ Standard Error } & \multicolumn{1}{c}{ t Stat } & P-value & Lower 95\% & Upper 95\% \\
\hline Intercept & 25,469 & 13,274 & 1,919 & 0,059 & $-0,999$ & 51,937 \\
$\mathrm{P}$ & $-0,078$ & 0,011 & $-6,889$ & 0,000 & $-0,101$ & $-0,056$ \\
$\mathrm{v}$ & 0,166 & 0,028 & 5,846 & 0,000 & 0,109 & 0,223 \\
$\mathrm{p}$ & 1,373 & 1,918 & 0,716 & 0,477 & $-2,452$ & 5,198 \\
\hline
\end{tabular}

Table 5. First results of regression analysis 
Calculated $F$ test value $\left(F_{\text {stat }}=27,379\right)$ is greater than the critical $F$ value $\left(F_{\text {crit }}=2,734\right)$ for $\alpha=0,05$ level of significance with 3 and 71 degrees of freedom which means that there is at least one regression coefficient $b_{i}(i=$ $1,2,3)$ different from zero. Comparing statistical $t$ values with critical $t$ value, as well as comparing $p$ values with $\alpha=$ 0,05 it can be seen that $b_{1}$ and $b_{2}$ regression coefficients are statistically different from zero, while $b_{3}$ is zero as shown in (1), (2) and (3).

$$
\begin{aligned}
& b_{1}: t_{\text {stat }}(P)=-6,889<t_{\text {crit }}=-1,99 ; p-\operatorname{value}(P)=0<\alpha=0,05 ; \quad \Rightarrow \quad b_{1} \neq 0 \\
& b_{2}: t_{\text {stat }}(v)=5,846>t_{\text {crit }}=1,99 ; p-\operatorname{value}(v)=0<\alpha=0,05 ; \quad \Rightarrow \quad b_{2} \neq 0 \\
& b_{3}: t_{\text {crit }}=-1,99<t_{\text {stat }}(p)=0,716<t_{\text {crit }}=1,99 ; p-\operatorname{value}(p)=0,477>\alpha=0,05 ; \Rightarrow \quad b_{3}=0
\end{aligned}
$$

Since assist gas pressure is not significant variable, regression analysis was done again, this time with cutting speed and laser power as independent variables. Regression analysis results are presented in table 6.

\begin{tabular}{lr}
\hline \multicolumn{1}{c}{ Regression Statistics } \\
\hline Multiple R & 0,656 \\
R Square & 0,431 \\
Adjusted R Square & 0,415 \\
Standard Error & 4,163 \\
Observations & 75 \\
\hline
\end{tabular}

\begin{tabular}{lrrrrr} 
ANOVA & df & \multicolumn{1}{c}{ SS } & \multicolumn{1}{c}{ MS } & F & Significance F \\
\hline Regression & 2 & 943,428 & 471,714 & 27,219 & 0,000 \\
Residual & 72 & 1247,785 & 17,330 & & \\
Total & 74 & 2191,213 & & & \\
\hline
\end{tabular}

\begin{tabular}{lrrrrrr}
\hline & Coefficients & Standard Error & \multicolumn{1}{c}{ t Stat } & P-value & Lower 95\% & Upper 95\% \\
\hline Intercept & $-28,259$ & 7,766 & $-3,639$ & 0,001 & $-43,740$ & $-12,778$ \\
$\mathrm{P}$ & 0,002 & 0,007 & 0,365 & 0,716 & $-0,011$ & 0,016 \\
$\mathrm{v}$ & 0,125 & 0,017 & 7,369 & 0,000 & 0,091 & 0,159 \\
\hline
\end{tabular}

Table 6. Second results of regression analysis

For $\alpha=0,05$ level of significance with 2 and 72 degrees of freedom $F_{\text {crit }}=3,124$. From table 4 it can be seen that $F_{\text {stat }}=27,219 . F$ test shows that at least one out of two regression coefficients is different from zero. Comparing $t_{\text {stat }}$ values for each regression coefficient with critical $t$ value $\left(t_{c r i t}= \pm 1,99\right)$ it can be concluded that laser power is not significant variable in the model. Finally, regression analysis with cutting speed as only independent variable was performed. Results of regression analysis are presented in table 7.

\begin{tabular}{|c|c|c|c|c|c|}
\hline & df & SS & MS & $\mathrm{F}$ & Significance F \\
\hline Regression & 1 & 941,113 & 941,113 & 54,957 & $\overline{0,000}$ \\
\hline Residual & 73 & 1250,099 & 17,125 & & \\
\hline Total & 74 & 2191,213 & & & \\
\hline
\end{tabular}

\begin{tabular}{lr}
\hline \multicolumn{2}{c}{ Regression Statistics } \\
\hline Multiple R & 0,655 \\
R Square & 0,429 \\
Adjusted R Square & 0,422 \\
Standard Error & 4,138 \\
Observations & 75 \\
\hline
\end{tabular}

\begin{tabular}{|c|c|c|c|c|c|c|}
\hline & Coefficients & Standard Error & t Stat & $\mathrm{P}$-value & Lower 95\% & Upper 95\% \\
\hline Intercept & $-26,023$ & 4,754 & $-5,474$ & 0,000 & $-35,499$ & $-16,548$ \\
\hline $\mathrm{V}$ & 0,125 & 0,017 & 7,413 & 0,000 & 0,092 & 0,159 \\
\hline
\end{tabular}

ANOVA

Table 7. Third results of regression analysis 
From table 5 it can be seen that cutting speed is significant variable since $t_{\text {stat }}=7,413>t_{\text {crit }}=1,99$. Regression equation for the cut perpendicularity $U$ is given by (4).

$$
U=-26,023+0,125 \cdot v
$$

Figures 1 and 2 depict diagrams of residuals and standardized residuals respectively.

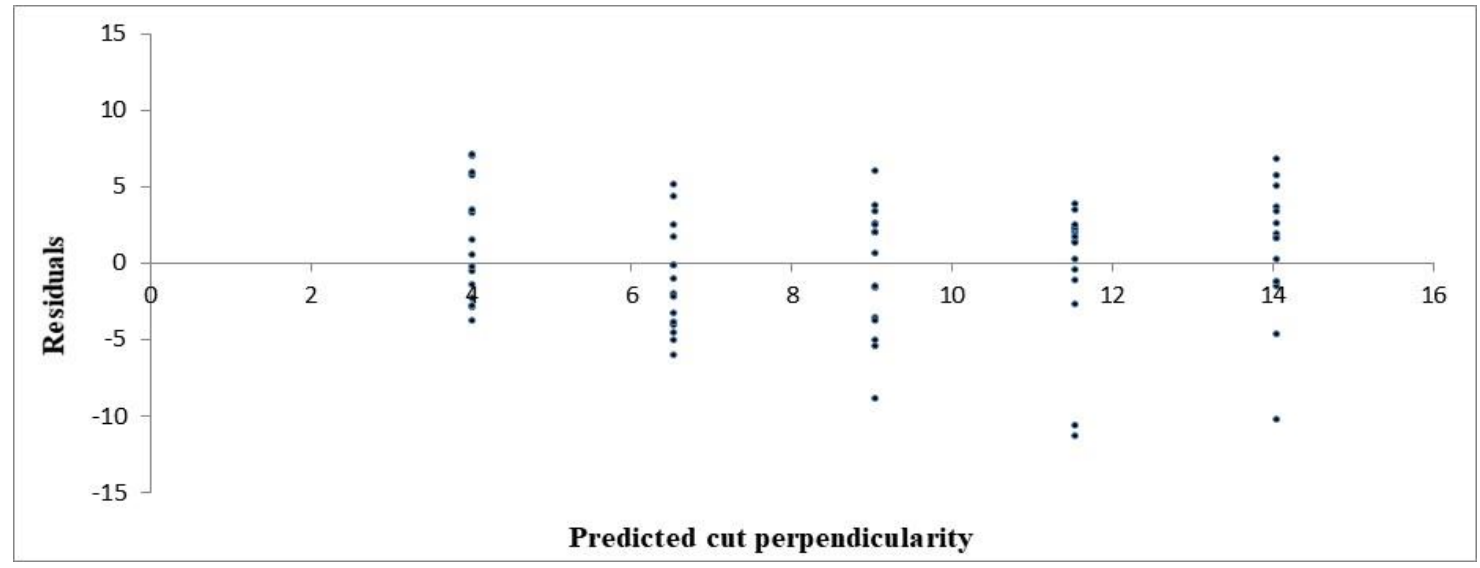

Fig. 1. Residuals vs. predicted cut perpendicularity

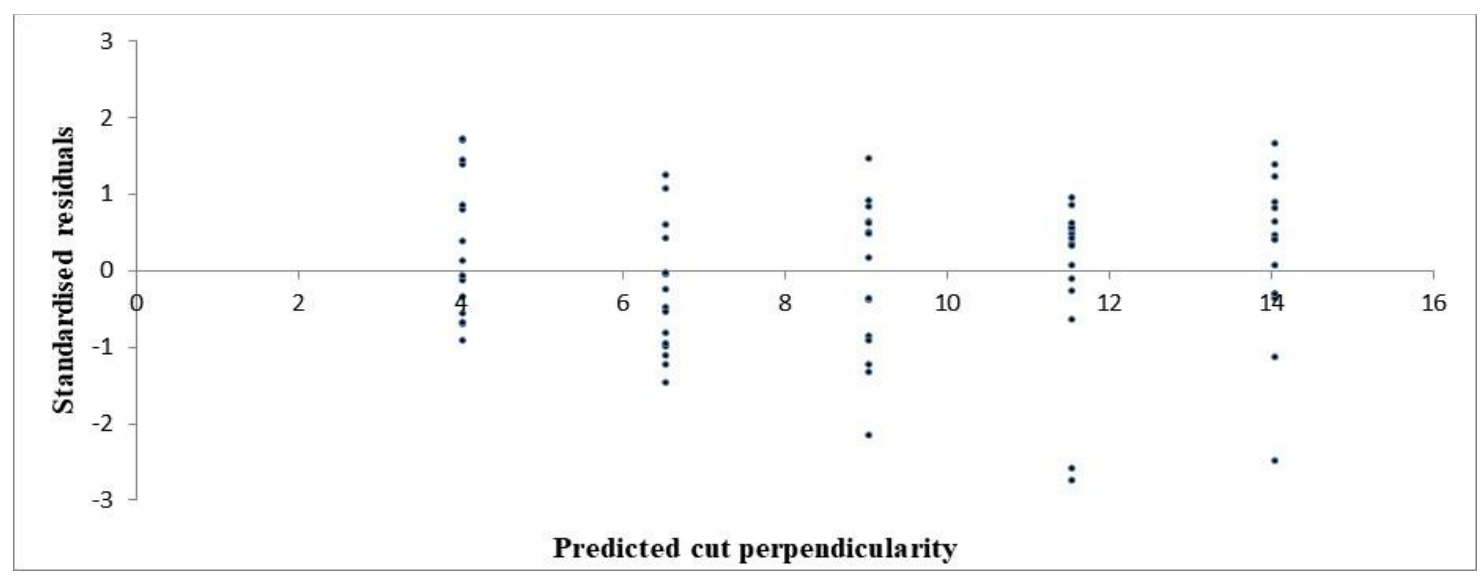

Fig. 2. Standardized residuals vs. predicted cut perpendicularity

From figures 1 and 2 it can be seen that the values of residuals are located around zero value without visible pattern, while standardized residuals are within three standard deviations. There are no extreme values of residuals and it can be concluded that regression equation is suitable to predict cut perpendicularity with respect to cutting speed. Histogram of residuals is depicted on figure 3.

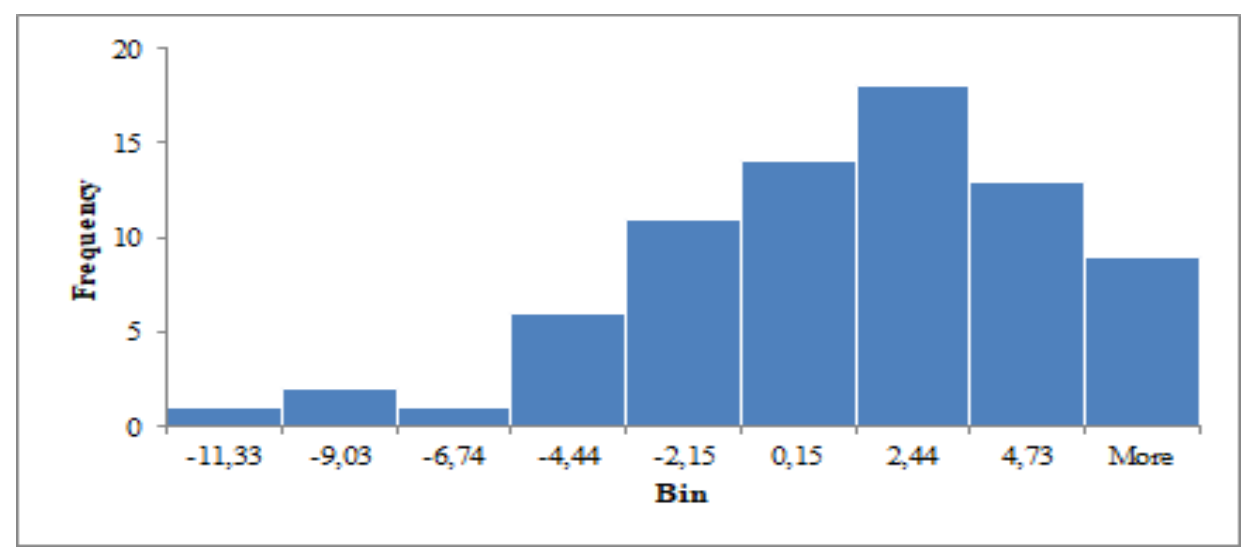

Fig. 3. Histogram of residuals 
From figure 3 it can be seen that the residuals are approximately normally distributed and that the condition of normality of residuals is satisfied.

Coefficient value for the cutting speed is 0,125 which means that with the unit change of cutting speed the cut perpendicularity change is 0,125 . Standardized coefficient value for cutting speed is 0,356 which means that with unit change of standard deviation of cutting speed, the change of the cut perpendicularity is 0,356 standard deviation. Since coefficient of determination is $R^{2}=0,429$, it can be concluded that $42,9 \%$ of variability of the cut perpendicularity is explained with variability of the cutting speed.

\section{Verification of results according to ISO standard}

During the experiment for the each sample average cut perpendicularity was computed, so 75 values of the variable cut perpendicularity was obtained. Since cut perpendicularity depends on the cutting speed, diagram of the cut perpendicularity vs. cutting speed was made as presented in figure 4. Diagram shows average values of cut perpendicularity, as well as horizontal line which presents the border of the first quality category of the cut perpendicularity according to ISO 9013:2002 (E) standard.

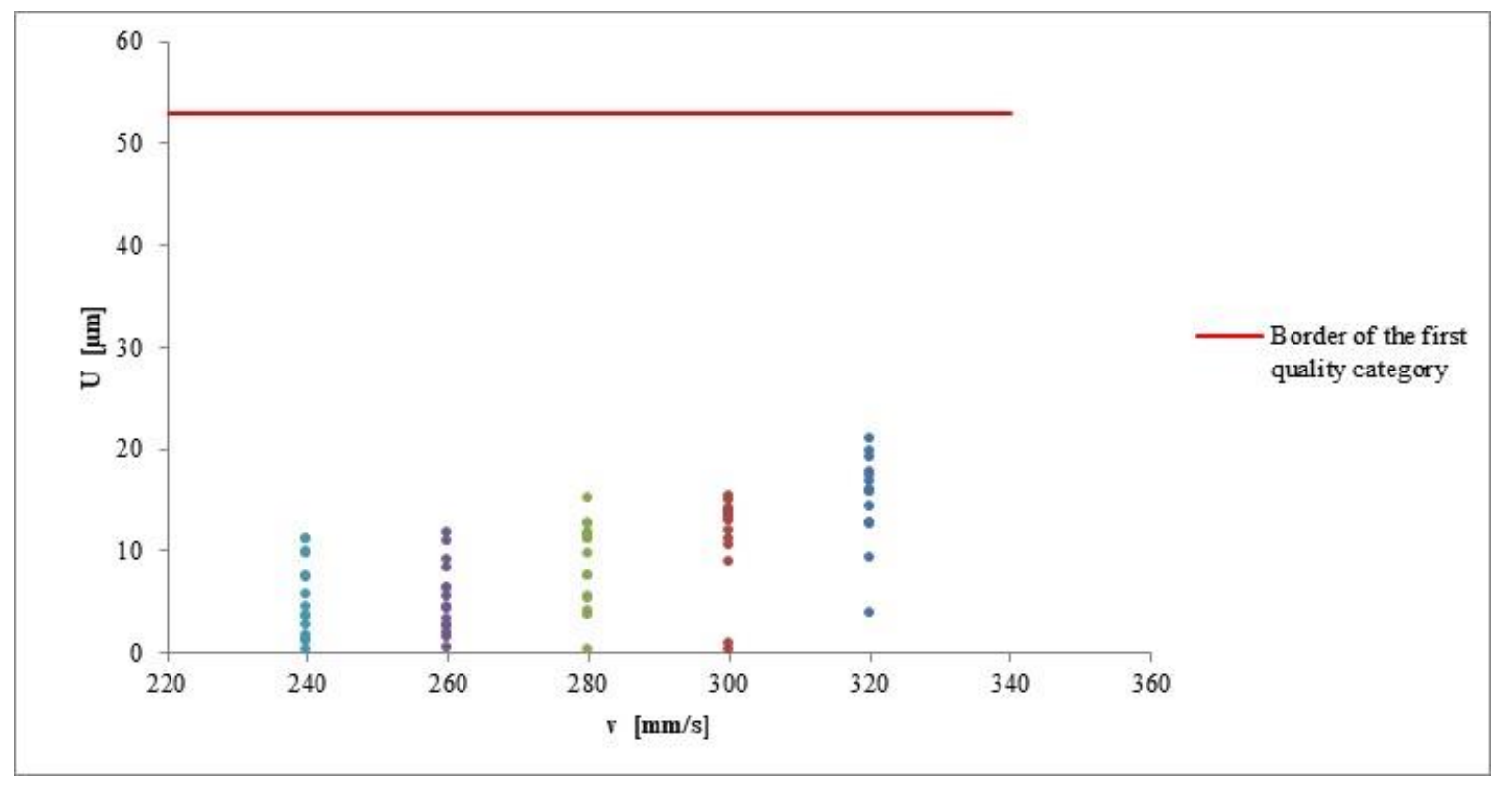

Fig. 4. Cut perpendicularity values

From figure 4 it can be seen that all average values of the cut perpendicularity are located well beyond the border of the first quality category of the cut perpendicularity according to ISO 9013:2002 (E) standard. It means that there are no large deviations of the kerf width at input and output side of the laser beam.

\section{Conclusion}

In this research the stainless steel $1.4307 \mathrm{DIN}, 1 \mathrm{~mm}$ of thickness was cut by HSG fiber laser. The effect of laser power, cutting speed and assist gas pressure on the cut perpendicularity was examined. Backward elimination linear regression analysis was used to create mathematical model for the estimation of the laser cut perpendicularity. From the regression model, it can be concluded that cutting speed is the only significant independent variable and that $42,9 \%$ variability of the cut perpendicularity is explained by the cutting speed. According to the model, cut perpendicularity increases with the increase of the cutting speed.

Analysis of residuals shows that there is no visible pattern. Also, analysis of standardized residuals shows that all standardized residuals are within three standard deviations. Histogram of residuals shows that residuals are approximately normally distributed. It can be concluded that there are no extreme measured values and that the obtained regression model is suitable to predict values of the laser cut perpendicularity depending on the cutting speed.

Every experimental value of the cut perpendicularity is located in the first quality category according to ISO 9013:2002 (E) standard. The recommendation could be to use the highest experimental speed of $320 \mathrm{~mm} / \mathrm{s}$ so to increase efficiency of the cutting process.

In the future research experiment with the same combination of the laser power and assist gas pressure values could be performed, but to use higher cutting speeds. In that way, it can be determined at which cutting speed the value of the cut perpendicularity moves into the second category of the quality according to ISO 9013:2002 (E) standard. 


\section{References}

[1] Levine, D. M.; Stephan D. F.; Krehbiel, T. C. \& Berenson, M. L. (2006). Business statistics, a first course, sixth edition, Pearson Education Inc., ISBN 0-13-611349-4, New Jersey

[2] Al-Sulaiman, F. A.; Yilbas, B. S. \& Ahsan M. (2006). $\mathrm{CO}_{2}$ laser cutting of a carbon/carbon multi-lamelled plainweave structure, Journal of Material Processing Technology, Vol. 173, No. 3, (April 2006) page numbers (345-351), ISSN 0924-0136

[3] Yan, Y.; Lin, L; Kursad S.; Wei W.; David W.; Lingfei J.; Yong B. \& Yijian J. (2011). CO2 laser underwater machining of deep cavities in alumina, Journal of the European Ceramic Society, Vol. 31, No. 15, (December 2011) page numbers (2793-2807), ISSN 0955-2219

[4] Avanish, K. D. \& Vinod, Y. (2008). Laser beam machining - A review, International Journal of Machine Tools \& Manufacture, Vol. 48, No. 6, (May 2008) page numbers (609-628), ISSN 0890-6955

[5] Cekic, A.; Begic-Hajdarevic, D; Kulenovic, M. \& Omerspahic, A. (2013). $\mathrm{CO}_{2}$ laser cutting of alloy steels using $\mathrm{N}_{2}$ assist gas, Procedia Engineering, Vol. 69, page numbers (310-315), ISSN 1877-7058

[6] Baumeister, M.; Dickmann, K. \& Hoult, T. (2006). Fiber laser micro-cutting of stainless steel sheets, Applied Physics A, Vol. 85, No. 2, (November 2006) page numbers (121-124), ISSN 0947-8396

[7] Begic-Hajdarevic, D.; Pasic, M.; Vucijak B. \& Cekic A. (2016). Statistical process control of surface roughness during CO2 laser cutting using oxygen as assist gas, Proceedings of the $26^{\text {th }}$ DAAAM International Symposium, ISSN 1726-9679, ISBN 978-3-902734-07-5, Katalinic, B. (Ed.), pp. 0247-0255, Published by DAAAM International, Vienna, Austria, DOI:10.2507/26th.proceedings.034

[8] Jarosz, K.; Löschner, P. \& Nieslony, P. (2016). Effect of cutting speed on surface quality and heat-affected zone in laser cutting of 316L stainless steel, Procedia Engineering, Vol. 149, page numbers (155-162), ISSN 1877-7058

[9] Rajaram, N.; Sheikh-Ahmad, J. \& Cheragi, S. H. (2003). $\mathrm{CO}_{2}$ laser cut quality of 4130 steel, International Journal of Machine Tools \& Manufacture, Vol. 43, No. 4, (March 2003) page numbers (351-358), ISSN 0890-6955 